\title{
Instituto Brasileiro de Bibliografia e Documentação (I.B.B.D)
}

\author{
SyLvio CorRÊA DE AvelLAR
}

\begin{abstract}
$\mathrm{C}$
oM o objetivo de tornar mais fácil, mais eficiente e mais econômica, a realização do trabalho intelectual, técnico ou científico, vêm sendo organizados, em todo o mundo, centros de documentação, pesquisa bibliográfica e informações, tendo como principais objetivos - pesquisar, selecionar, reunir, classificar, catalogar e divulgar informações bibliográficas e documentar. A palavra de ordem é - organizar os recursos meios para que os técnicos e cientistas possam dedicar-se mais profundamente às atividades afins.

No Brasil, a indústria, as universidades e os centros de investigação científica, que, presentemente estão vivendo um promissor período de reformas, reorganização e desenvolvimento, lutam ainda contra a deficiência de documentação bibliográfica especializada e adequada. Os nossos centros de estudos e pesquisas trabalham isolada e paupèrrimamente, não havendo coordenação, intercâmbio ou colaboração, elementos imprescindíveis na vida moderna em que tudo se agiganta.
\end{abstract}

A UNESCO, trabalhando pelo progresso da educação e da cultura entre os povos, tem procurado estimular e orientar a organização de centros de bibliografia. Desde 1950, essa organização internacional vinha tendo entendimentos com instituições brasileiras, no sentido de que fôsse estabelecido. no Brasil, um centro de bibliografia que, possivelmente, no futuro, viesse a estender sua ação a tôda a América do Sul.

A Fundação Getúlio Vargas, que desde 1947 voltara sua atenção para os problemas de documentação e biblioteconomia, pelo reconhecimento da importância dêsses elementos meios para levar avante objetivos mais importantes, tanto que criara, juntamente com o Departamento Administrativo do Serviço Público, um Serviço de Intercâmbio de Catalogação, entrou emacôrdo com a UNESCO para estudar e promover a organização de um Centro brasileiro de bibliografia e documentação. Estudos e planos foram elaboràdos, com a observância das necessidades e peculiaridades brasileiras e com o exame da experiência dos países mais adiantados.

Com a criação do Conselho Nacional de Pesquisas, surgiu mais um órgão profundamente necessitante de serviços de documentação e bibliografia, não só de literatura nacional, mas especialmente universal. Ficaram, assim, interessados no problema - Conselho Nacional de Pesquisas, Fundação Getúlio Vargas, Instituto Brasileiro de Educação, Ciência e Cultura (representação da UNESCO no Brasil). Interessados diretamente, e dedicados a 


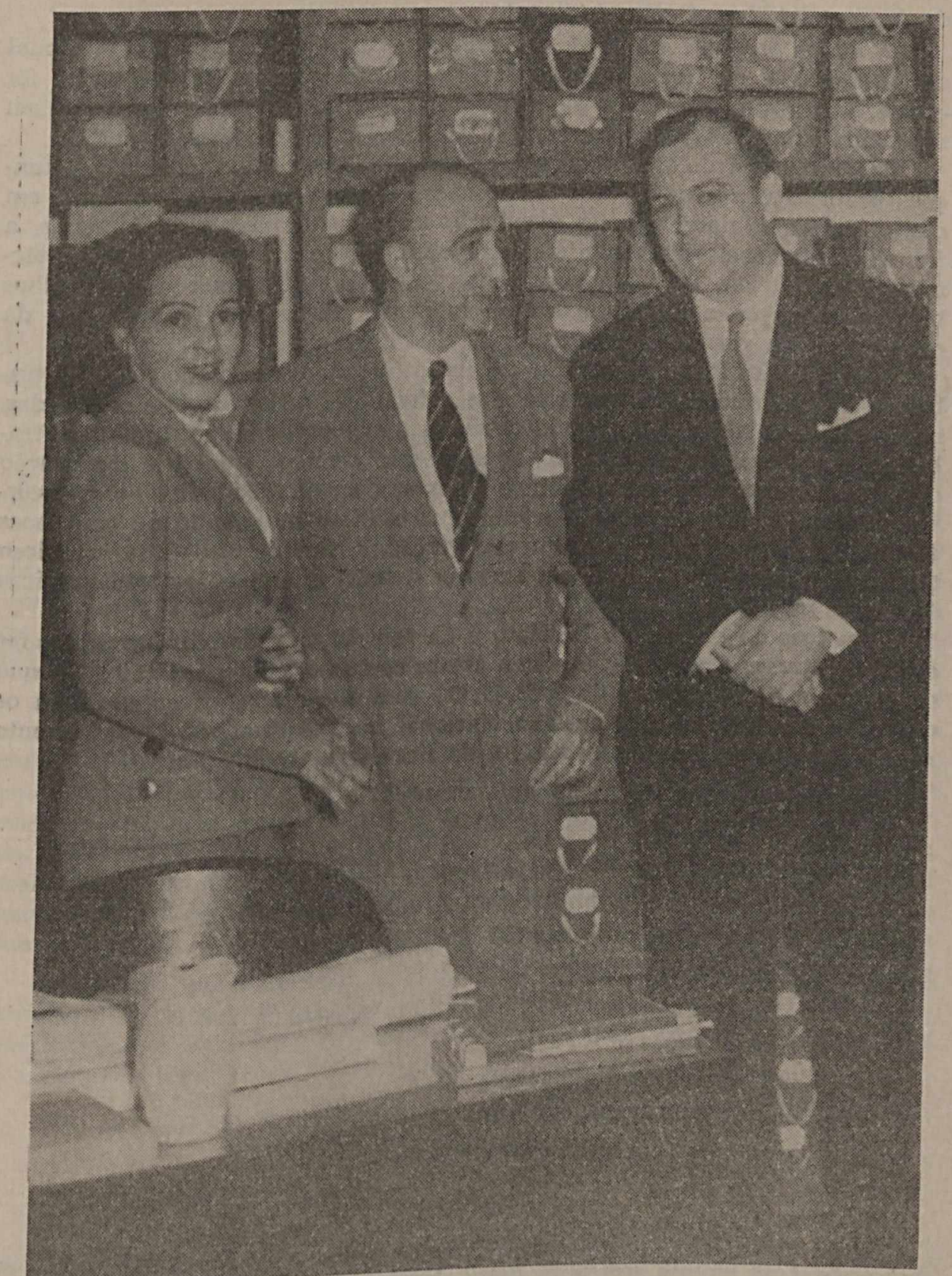

O Sr. Luther Evans, Diretor-Geral da UNESCO, ex-Diretor da "Library of Congress", visita o Serviço de Intercâmbio de Catalogação, sendo recepcionado pelo Presidente do I.B.B.D., Sra. Lídia Sambaqui, e pelo Presidente da Fundação Getúlio Varǵas, Dr. Luís Simões Lopes 
uma solução rápida, pois interessados na obra era todo o País, por tratar-se de um serviço de interêsse nacional.

A 27 de fevereiro de 1954, por proposta conjunta do Conselho Nacional de Pesquisas e da Fundação Getúlio Vargas pelo Decreto n. ${ }^{\circ} 35.124$, foi criado o Instituto Brasileiro de Bibliografia e Documentação, que teve seu regimento aprovado pelo Decreto n. 35.430 , de 29 de abril de 1954.

No programa de trabalho para o Instituto, foram-lhe atribuidas - funções próprias dos centros de documentação especializados, já existentes em outros países, e ainda aquelas peculiares aos centros bibliográficos gerais, a fim de tornar mais fácil, não só o trabalho nas instituições científicas, técnicas e industriais, mas ainda colaborar no desenvolvimento dos trabalhos biblioteconômicos e bibliográficos de interêsse básico para o progresso da educação e da pesquisa no Brasil.

Ficou o Instituto incumbido de incentivar o desenvolvimento dos trabalhos bibliográficos em execução nas diferentes instituições especializadas, auxilianço e colaborando, quando desejada a sua participação direta nos trabalhos em execução, e evitando, sempre que possível, qualquer duplicação de serviço. Incumbido ainda de inventariar as disponibilidades de nossos acêrvos bibliográficos e de enviar os melhores esforços no sentido de unir êsses ¿cêrvos através da mais perfeita cooperação, a fim de que cada estudioso tenha, permanentemente, ao seu serviço, o total das coleções bibliográficas existentes no País.

Em face da origem do Instituto e da relação que tem com as entidades que fomentaram a sua criação, ficou estabelecido no Decreto n. ${ }^{\circ} 35.124$, que - programa de atividades do I.B.B.D. será executado, de acôrdo com os abjetivos e interêsses do Conselho Nacional de Pesquisas, do Departamento Administrativo do Serviço Público, e da Fundação Getúlio Vargas.

São os seguintes, os órgãos que compõem o I.B.B.D. :

I - Conselho Diretor (C.D.)

II - Direção Executiva (D.E.)

III - Serviços de Informações Técnico-Científicas (S.I.T.C.)

IV - Serviço de Bibliografia (S.B.)

$\mathrm{V}$ - Catálogo Coletivo (C.C.)

VI - Serviço de Intercâmbio e Catalogação (S.I.C.)

VII - Biblioteca (Bt.)

VIII - Serviço de Publicações (S.P.)

IX - Laboratório de Reproduções Fotográficas (L.R.F.)

X - Serviço de Administração (S.A.)

\section{SUMMARY}

Documentation, bibliography and information centres at the service of science and technology. Lack of such centres in Brazil. Scholars and research workers, universities and industrial plants confronted with the precariousness of documentation. Absence of coordination and cooperation. The UNESCO and the project towards the creation of the Braziiian Institute of Bibliography and Documentation; stages of development of the project and the final establishment of the Institute, in 1954. The Service of Catalogiving Intercourse as a predecessor of the Institute. The organization and functions of the Institute. The organization and functions of the Institute briefly described. 